\title{
Autonomous Learning and Metacognitive Strategies Essentials in ESP Class
}

\author{
Parviz Ajideh \\ Tabriz University \\ Tabriz-Iran \\ E-mail: Parviz_333@yahoo.com
}

\begin{abstract}
The reform in teaching and curriculum involves not only in the teaching content, but more so in teachers' methodology, the students' learning strategies and the changed relationship between students and teachers in the classroom setting.

The purpose of this paper is to suggest that what is needed for ESP is a different orientation to English study and to outline an approach which departs from that which is generally taken. Broadly, what is involved is a shift of the focus of attention from the grammatical to the communicative properties of language. This view that the difficulties which the students encounter arise not so much from a defective knowledge of the system of language but from unfamiliarity with English use is acceptable but not sufficient.

It is suggested that although specification of language needs is necessary for ESP course and it will be useful for selecting and grading materials, in teaching ESP learning strategies should play an important role. Accordingly, autonomous learning and metacognitive strategies are suggested as basic essentials for teaching and learning ESP.
\end{abstract}

Keywords: Autonomy, Cognition, Metacognition, Product, Process, ESP, Goal-oriented, Course design

\section{Introduction}

English for specific purposes (ESP) is a movement based on the proposition that all language teaching programs should be tailored to the specific learning and language use needs of identified groups of students

After the Second World War English became the accepted international language of technology, science, and commerce, it created a new generation of learners who knew specifically why they were learning the language. In fact there was a pre-determined goal in their learning English. Whereas English had previously decided its own destiny, it now became subject to needs, and demands of people other than language teachers. Dovey (2006) states courses which prepare students for the workplace in specific ways can be expected to have purposes quite different from those of disciplinebased courses and can also be expected to introduce new questions.

ESP also became an important part of English -as-second language teaching in the 1970s and 1980s, probably as a direct result of the introduction of communicative teaching curricula. Its main drive was practical, driven by the increasing numbers of people around the world who needed English for clearly defined reasons such as reading academic textbooks or transacting business (Hutchinson and Waters, 1987). It is suggested that ESP could easily be outlined based on the sorts of texts that learners need to become familiar with, or the needs-related nature of the teaching (Swales, 1985). The early analyses of ESP texts took the form of frequency counts of structures or verb forms, but such analyses only provided descriptions and had little or no explanatory force. These limitations, together with the increasing importance of the communicative aspects of language and an increasing interest in linguistic use rather than form, led to researchers using rhetorical or discourse analysis methods to discover the main characteristics of texts in different academic fields (e.g. Widdowson, 1979).

During the late 1970s ESP course designers started to carry out needs analysis of their students' future linguistic requirements. These needs analysis were often expressed in terms of notions and functions (Wilkins, 1976) and the most celebrated model of such a needs analysis are described by Munby (1978) in his communicative syllabus design in which he presented a system for devising appropriate syllabus specification from adequate profiles of communicative needs. These profiles included the purposes of communication, the communication settings, and the language skills, functions and structures required.

We can trace an acceptable work during 60s and 70s in teaching and learning English in Iran in corporation with the institutions in the U.K. or the U.S.A. Iran-America Society, and the British council were more active in offering general English courses. The major Iranian universities established scientific relations with the institutions in America and 
England, for example Shiraz University with the University of Pennyselvania, Tehran University with the University of Illinios, and Tabriz University with British Council. These scientific ties helped for the emergence loosely defined ESP, a kind of English narrowed in scope to meet the specific needs of the students.

In early 1981 Curriculum development comities started functioning. The English committee asked different universities to compile textbooks with ESP flavor without providing them with any specific framework. In 1985 SAMT was responsible for compiling and publishing textbooks in different areas of specializations. Accordingly more than one hundred sub-technical and technical textbooks have been published. Without saying it is evident that ESP is not equal for producing sub-technical and technical textbooks. As Celce-Murcia (2001) mentions ESP practitioners approach course development must consider a multitude of factors, and some essential questions, before, and during, project initiation.

In this regard Yarmohammadi (2005) claims that language teaching in Iran does not follow any specific purpose. The first and the most important thing we have to embark on is to verify and operationalize the objectives of language teaching and learning in Iran.

\section{Statement of Problem}

As an ESP teacher at Tabriz University for twenty years this question whether an English teacher courses or the specialists from the field should teach ESP course does not leave me. Some students think that ESP is a new label for GPE and nothing else. For them this is invented by English teachers to make students interested in English programs. They believe that their instructors in their field will be more successful to teach ESP courses even not being familiar with English teaching and learning theories. For some others having knowledge in the field is not sufficient for an ESP Instructor, they should have a good command in general English and they should be familiar with the basic principles and teaching and learning theories.

\subsection{Review and Discussion}

To pave the way, it is better to have a brief look at some definitions and explanations by some specialists in the field to support the idea that ESP is not the same as EGP. One of the generally accepted definitions refers to Huthinson and Waters. What is the difference between the ESP and General English (EGP) approach? Hutchinson and Waters (1987:53) answer this quite simply, “... in theory nothing, in practice a great deal”. This definition by Hutchinson and waters raises one important question. If in theory there is no difference between ESP and EGP, what is the theoretical justification for ESP? It seems that without a theoretical justification to ESP there will be no acceptable rational for such a course.

But Widdoson (1983) attempts to theorize ESP and this can be followed in his works under two interrelated headings: Learning purpose and Language use.For Widdowson GPE is no less specific and purposeful than ESP. What distinguishes them is the way in which purpose is defined, and the manner of its implementation. Based on this definition there are two interpretations from learning purpose. One might be regarded as objective- oriented learning and the other as aim-oriented one.In ESP Specification of objective is equivalent to aim that is a training operation and deals with development of restricted competence. Whereas, in GPE Specification of objective is not equivalent to aim but it leads to aim that is an educational operation and deals with development of general capacity. The following quotation (Widdowson, 1983) clarifies the point:

...ESP is essentially a training operation which seeks to provide learners with a restricted competence to enable them to cope with certain clearly defined tasks. These tasks continue the specific purposes which ESP course is designed to meet. The course, therefore, makes direct reference to eventual aims. GPE, on the other hand, is essentially an educational operation which seeks to provide learners with a general capacity to enable them to cope with undefined eventualities in the future. (p.6)

To suggest his model of language use, Widdowson (1983) criticizes the two models of idealization, registers analysis and needs analysis and suggests his own model of idealization.

1. Register analysis approach is a kind of idealization that involves the dissociation of linguistic forms from their communicative function in discourse. In fact the specification based on register analysis does acknowledge the pedagogically necessary distinction between aims and objectives. It rests on the assumption that a definition of objectives in terms of linguistic terms will provide for the subsequent satisfaction of communicative aims. That is to say that the imparting of linguistic competence will enable the learner to develop communicative capacity under his own steam. In this respect, it allows for learning to take place beyond the limits of the teaching input. So it is based on educational theory.

2. Needs analysis approach is a kind of idealization that seeks to retain the communicative value of linguistic elements and analyses language into its notional and functional. What this needs analysis approach seeks to do is to bring aims 
into closer approximation to objectives. Here, findings that emerge from needs analysis characterize aims. This is, in fact, the orthodox view of ESP course design.

This idea can also be followed in methodology literature where ESP is considered as the natural product of Notional functional approach to language teaching. Richards and Rogers (2001) state that a notional functional syllabus would include not only elements of grammar and lexis but also specify the topics, notions, and concepts the learner needs to communicate about. The English for specific Purpose (ESP) movement likewise begins not from a structural theory of language but from a functional account of learner needs.

As it mentioned earlier, Widdowson challenges this orthodox view of ESP and he suggests a discourse approach to ESP. For him what we must look for is a model of language, using which does not simply atomize the user's behaviour into components of competence, but which accounts for the essential features of the discourse process. At the same time, such a model should provide us with the means of characterizing ESP at different points on the scale of specificity and consistent with the distinctions I have proposed in the preceding chapter. The model therefore has to lend support to the concepts of training and education, of competence and capacity, of aims and objectives, and so give us a theoretical basis for ESP (Widdowson 1983:34). For Widdowson the register analysis and needs analysis approach to ESP focus on systematic knowledge whereas in his suggested discourse process approach both systemic knowledge and schematic knowledge are involved.

Hutchinson and Water (1987) challenge this view and claim that ESP must be seen as an approach not as a product, ESP is not a particular kind of language or methodology, nor does it consist of a particular type of teaching material, it is an approach to language learning, which is based on learner need.

It seems that in the three approaches stated earlier (register analysis, needs analysis and discourse process approaches) the idea of what to learn plays an important role and how learn is not the main concern. The following quotation from Hutchinson and Waters (1987) is to support this idea.

.... But our concern in ESP is not with language use -although this will help to define the course objectives our concern is with language learning. We cannot simply assume that describing and exemplifying what people do with language will enable someone to learn it. If that were so, we need to do no more than read a grammar book and a dictionary in order to learn a language. A truly valid approach to ESP must be based on an understanding of the processes of language learning." (p.24)

There is a need to an attempt to seek possibilities of fostering learner autonomy in ESP course design in Iranian EFL teaching context. This importance can be followed by applying metacognitve strategies for ESP learning. In fact, an autonomous learner should be able to manage or regulate the process of learning which involves making decisions as to what to learn, how to learn, when to monitor, and in what way to evaluate success or failure of learning (Wenden 1987; Holec 1987; cotteral 2000).

\section{2 Goal-oriented and Process-oriented Syllabuses}

Generally speaking, the process of deciding what to teach is based on consideration of what the learner should most usefully be able to communicate in the foreign language. In ESP, According to Mackay and Mountford (1978) when needs are clear, learning aims can be defined in terms of these specific purposes to which the language will be put, whether it be reading scientific papers or communicating with technicians on an oil rig. The result is that almost immediately, teaching can be seen to be effective in that the learner begins to demonstrate communicative ability in the required area. What Mackay and Mountford suggest is only the realm of Goal-oriented syllabus and there is no place to processes-oriented one in such an interpretation of the learner needs.

We know goal-oriented approach focuses on the selection of language by reference to the ends of learning, but the process-oriented approach focuses on the presentation of language by reference to the means of learning and allows the ends to be achieved by the learner by exercising the ability he or she has acquired. The first approach assumes that the completion of a course of instruction marks the completion of learning and that all that is left for the student to do is to apply this ready-made knowledge. The second approach assumes that learning will continue beyond the completion of instruction since the aim of such instruction precisely is to develop a capacity to learn: it does not itself realize any special purpose but provides the learner with the potential for its realization.

In practice, syllabuses in which the selection and grading of items was carried out on a grammatical basis fell into disfavor because they failed adequacy to reflect changing views on the nature of language. In addition, there was sometimes a mismatch between what was taught and what was learned. Some SLA researchers have claimed that this mismatch is likely to occur when the grading of syllabus input is carried out according to grammatical rather than psycholinguistic principles, while others suggest that the very act of linguistically selecting and grading input will lead to distortion. Moreover it seemed that functional-notional principles would result in syllabuses which were radically different from those based on grammatical principles. However, in practice, the new syllabuses were rather similar to 
those they were intended to replace. In both syllabuses, the focus tended to be on the end products or results of the teaching / learning process.

According to Widdowson (1983) the absence of distinction between aims and objectives leads to an ambiguity in the expression "learner needs". On the one hand, it can refer to what the learner has to do with the language once he has learned it: in this sense it has to do with aims. On the other hand, it can refer to what the learner has to do in order to learn: in this sense, it relates to pedagogic objectives.

If one follows a goal-oriented approach one needs to take one's bearing from models of linguistic description, since these will define the units of course content. A process-oriented approach, on the other hand, can only be pursued by reference to some idea about how to learn. In this regard, according to Atay (2007) the interest in the strategies has paralleled a movement away from a dominantly teaching -oriented perspective to one that emphasis the learner's active role in the learning process. Thus, if ESP is an approach not as a product, it must be an approach to language learning. And here, Learning strategies and activities should play more important role than selecting and grading appropriate materials to meet the students' needs.

\section{3 Learner Autonomy}

Holec (1987) defines Learner autonomy as the ability to take charge of one's learning.

It is good for teachers introduce such key concepts as "learner-centeredness" and Learner autonomy" and their theoretical underpinning, and stress the importance of learning how to learn so that students would be psychologically prepared and are likely to cooperate. As learner-centeredness is one of the tendencies that support autonomous language learning, students should be given a clear explanation as to what it means, how it is conducted, and what benefits could be gained through this approach. Aebersold and Field (1997) define the term" student-centered and describe its advantages as the following:

Courses in which the students have some degree of control over what goes on in the course and how it

occurs are considered to be student-centered...........Giving students some control over their learning process has many benefits: It makes them feel confident; it puts some of the decision making in their hands; it puts the responsibility for learning in their hands; and over the long term it builds independence and self-reliance so that they can read on their own without being dependent on teacher direction and supervision. It activates the students' own learning spirals. (P, 37).

Even giving students' freedom to choose materials is not only compatible to the theory, but also satisfies learners' needs. A better understanding of the theory would stimulate learners' interest and motivation to practice autonomous learning. Thus consciousness raising was chosen as the first measure to implement the innovation. To transfer the responsibility of selecting materials to learners is supported by (Hollec, 1987, Vitori, 1995), because it stimulates their interest, enhance the do-it-yourself ability. To my own experience engaging learners in activities of selecting, preparing and presenting materials could be considered creative because these activities involve problem-solving and decision -making.

\section{4 Cognitive Strategies}

The term cognitive strategy refers to specific measures or steps that learners take in order to fulfill learning tasks (O'Malley and Chamot 1990). Literature in reading research has shown that cognitive strategy use can facilitate understanding and successful learners seem to be differentiated from less successful ones in terms of strategy use. Similarly learners who possess summarizing skills (Kintch and Van Dijk 1978) have improved comprehension on the texts and increased recalls.

\section{5 Monitoring}

Monitoring refers to both learners' identifying learning difficulties and pointing out shortcomings of the program so that decision could be made as to what to do about it (Rubin 1987). As the shift of responsibilities from the teacher to the learners takes place, it is important for the learner to do self-evaluation and provide feedback to the program in order to regulate learning process. Nunan (1997) suggests that monitoring plays an important role in informing the learner of the problems encountered during the course of learning. Thus the course should intend to raise learners' consciousness to monitor their learning process.

\section{6 Metacognitive Strategies}

One can probably figure out from analyzing the term itself, metacognition is cognition about cognition or thinking about thinking. Thinking can be of what the person knows and what the person is currently doing. Metacognition is deliberate, planned, intentional, goal directed and future-oriented mental processing that can be used to accomplish cognitive tasks (Flavell, 1971). Metacognition involves active monitoring and consequent regulation and orchestration of cognitive processes to achieve cognitive goals. As metacognition involves an awareness of oneself as an actor, a 
deliberate storer and retriever of information, it may be reasonable to reserve the term metacognitive for conscious and deliberate thoughts that have other thoughts as their objects (Hacker, 1998).

According to Block (2004) metacognition can be defined as a reader's awareness of (1) what he or she is thinking about while reading, (2) what thinking processes he or she initiates to overcome literacy challenges, and(3) how a reader selects specific thinking processes to make meaning before, during, and after reading .

Auerbach and Paxton (1997), define metacognition as "knowledge of strategies for processing texts, the ability to monitor comprehension, and the ability to adjust strategies as needed" (pp. 240-41). Research studies (Duell, 1986) seem to confirm that as children get older they demonstrate more awareness of their thinking processes. Metacognition is relevant to work on cognitive styles and learning strategies in so far as the individual has some awareness of their thinking or learning processes.

Cognitive strategies differ from metacognitive strategies in that they are likely to be encapsulated within a subject area (e.g., EFL), whereas metacognitive strategies span multiple subject areas (Shraw, 1998).

Cognitive strategies are, for example, making a decision, translating, summarizing, linking with prior knowledge or experience, applying grammar rules and guessing meaning from texts (e.g., O'Malley and Chamot, 1990). Metacognition refers to awareness and control of cognitive activities. Empirical studies show that successful learners differ from less successful ones in both the quantity and quality of cognitive and metacognitive strategy use (e.g., Oxford, 1989).

The literature of metacognitive strategies in reading comprehension reveals that poor readers in general lack effective metacognitive strategies and have little awareness on how to approach to reading. They also have deficiencies in the use of metacognitive strategies to monitor for their understanding of texts In contrast, successful L2 readers know how to use appropriate strategies to enhance text comprehension (e.g., Pitts, 1983).

I have experienced metacognitive strategies with intermediate-level students in most of my ESP courses at Tabriz University, and in some cases I invited feedback from the students on their impressions and thoughts of the strategies covered during the terms. What follows are an indication of students' retrospective comments on the efficiency of these strategies at ESP class.

1. Now, I think my brain is more active in reading as if, I read with my brain rather than my eyes.

2. After previewing I can decide how I will deal with any particular text, and which other strategies I am going to follow to have better comprehension.

3. The strategies you applied made me conscious and active I used to read a text word for word until then, being afraid to misunderstand the contents. Now I'm trying to skip as many words as possible even when I am going to read about something not familiar, and I am going to deal with the text I have already had quite a few knowledge.

4. There are many positive aspects of using predictions. Firstly, we immediately thinking about the topics help us to understand contents of articles. Secondly, we can improve our reading speed by predicting the following contents. Thirdly, we can associate our knowledge we have concerning the topics and it can help to make our learning much easier.

5. Finding key words in any text was an interesting technique. I think relying on Key words is more helpful than relying on the structure in reading a text.

6. I think it is easier to ask question when I read something I have prior knowledge with because I have something to base in to ask question.

7. Now, I have a critical reading and I can use my background knowledge.

\section{Conclusion}

We conclude that ESP is an approach to language teaching which aims to meet the needs of particular learners. This means in principle that much of work done by ESP teachers is concerned with designing appropriate courses for various groups of learners. In fact, with ESP and content-based syllabuses, an obvious means of grading content is with reference to concepts associated with the subject in question

It seems reasonable enough to assume that a specification of language needs should define the language content of a course designed to meet such needs.Here "learner needs" is open to question. In fact two different interpretations may be extracted from learners needs. It may refer to terminal behavior, the ends of learning or it may refer to what the learner needs to do to actually acquire the language.

In recent year, some applied linguists have shifted focus from the outcomes of instruction, i.e. the knowledge and skills to be gained by the learner, to the processes through which knowledge and skills might be gained. Although specification of language needs is necessary for ESP course and it will be useful for selecting and grading materials, in 
teaching ESP, Learning strategies should play an important role. Accordingly, Autonomous learning and metacognitive strategies are suggested as the two basic essentials for teaching and learning ESP. Finally, if we limit teaching ESP to what to learn and forget how to learn, it will be safe to claim that familiarity with teaching and learning theories is not an essential for ESP teacher, otherwise it should be regarded as a sin qua non for ESP teacher.

\section{References}

Aebersold, J. A.M and M.L. Field. (1997). From Reader to Reading Teacher: Issues and Strategies for language classroom. Cambridge: Cambridge University Press.

Atay, D. (2007). Memory strategy instruction, contextual learning and ESP vocabulary recall. Journal of English for Specific Purposes, Volume 26, issue1.

Auerbach, E. R and Paxton, D. (1997). It's Not the English Thing": Bringing Reading Research Into ESL Classroom. TESOL Quarterly, 31,237-260.

Baker, L. and Brown, A. L. (1984). Metacognitive skills and reading. In P.D. Pearson (Ed.), Handbook of Reading Research Vol. 1, (pp. 353-394) New York: Longman.

Block, C. (2004). Teaching Comprehension: The Comprehension Process Approach, Texas Christian University, Pearson Education, Inc.

Brown, R. (2002). Straddling two worlds; Self-directed comprehension instruction for middle schoolers. In Block ,C, and Pressely, M. (eds.). Comprehension Instruction. Research Based Practice. NY; Guilford.

Celce-Murcia, Marianne. (2001). Teaching English as a Second or Foreign Language, Heine and Heine, Thomson Learning. U.S.A.

Collins, N.D. (1994). Metacgnition and Reading to learn. Eric Digest \# 96.

Cotteral, S. (2000). Promoting learner autonomy through the curriculum; Principles of designing language courses. ELT Journal 52/2; 109-117.

Dovey, Teresa. (2006). What purposes, specifically? Re-thinking purposes and specificity in the context of the new vocationalisn. Journal of English for Specific Purposes, Volume 25, issue 4.

Duell O.K. (1986). Metacognitive skills. In G. Phye, and T. Andre (Eds.), Cognitive Classroom Learning. Orlando, FL: Academic Press.

Flavell, J. H. (1971).First discussant's comments: what is memory development the development of? Human Development 14, 272-78.

Hacker, D. J. (1998). Definition and empirical foundations. In Hacker,D.J., Dunlosky. J. and Graesser,A.C., editors, Metacognition in Educational Theory and Practice. Mahwah, NJ: Erlbraum, 1-24.

Holec, H. (1987). The learner as manager: managing learning or managing to learn? In Wenden, and Rubin (eds.). Learner strategies in Language Learning. Prentice hall international. UKO Ltd.

Hutchinson T. and Waters A. (1987). English for specific Purposes: A learning Centered Approach. Cambridge: Cambridge University Press.

Kintch, w. and Van Dijk, T.A. (1978). Toward a model of discourse comprehension and production. Psychological Review 85; 363-394.

Mackay, R. and Mountford, A. (1978). English for Specific Purposes. Longman group Ltd.

Munby, J. (1978). Communicative Syllabus Design, Cambridge: Cambridge University Press.

Nunan, D. (1997). Strategy training in the language classroom; An empirical investigation. RELC Journal 26: 56-81.

O’Malley, M.J. and Chamot, A.U. (1990). Learning Strategies in Second Language Acquisition. .Cambridge: Cambridge University Press.

Oxford. R. (1989). The best and the worst: an exercise to tap perceptions of language -learning experiences and strategies. Foreign Language Annuals 22, 44-54.

Pitts, M. M. (1983). Comprehension monitoring: definition and practice. Journal of Reading . 26, 516-23.

Richards, J. and Rodgers, S. (2001). Approaches and Methods in Language Teaching. Cambridge University Press.

Rubin, J. (1987). Learner strategies: theoretical assumptions, research history and typology. In Wenden, and J. Rubin.(eds.). Learner strategies in language Learning. Prentice Hall International, (UK) Ltd.

Shraw, G. (1998). Promoting general metacognitive awareness. Instructional Science 26, 113-25.

Swales, J. (1985). Episodes in ESP, Perganon. 
Victori, M. (1995). Enhancing metacognition in self-directed language learning. System 23/2; 223-234.

Voller, P. (1997). Does the teacher have a role in autonomous language learning. In B, P. and P. Voller (eds.0. Autonomy and Independence in language learnin. New York: Addison Wesely Longman Limited. pp. 181-191.

Wenden, A. ( 1987). Learner Strategies in Language Learning. Prentice Hall International (UK) Ltd.

Widdowson, H.G. (1983). Learning Purpose and Language Use. Oxford: Oxford University Press.

Widdowson, H.J. (1979). Explorations in Applied Linguistics. Oxford University Press.

Widdowson.H. G. (1984). Explorations in Applied Linguistics, Oxford University press.

Wilkins, D. (1976). Notional Syllabuse. London: Oxford University Press.

Yarmohammadi, Lotfollah. (2005). ESP in Iran from language planning perspective, Proceedings of the First National ESP/EAP Conference, Volume 2. SAMT, Tehran. 